\title{
Angioscopic Study of Silent Plaque Disruption in Nonischemic Related Coronary Artery in Patients With Stable Ischemic Heart Disease
}

\author{
Zuoyan Wang, ${ }^{1}$ MD, Shigenobu InAmi, ${ }^{1}$ MD, Sonoko Kirinoki, ${ }^{1}$ MD, Hideo Yamamoto, ${ }^{1}$ MD, \\ Gen Takagi, ${ }^{1}$ MD, Satoshi Aoki, ${ }^{1}$ MD, Koji Kato, ${ }^{1}$ MD, Hitoshi Takano, ${ }^{1}$ MD, Kuniya Asai,,${ }^{1}$ MD, \\ Masahiro Yasutake, ${ }^{1} \mathrm{MD}$, Masamichi Takano, ${ }^{1} \mathrm{MD}$, Masatoshi Yamamoto, ${ }^{2} \mathrm{MD}$, Takayoshi Ohba, ${ }^{2} \mathrm{MD}$, \\ and Kyoichi Mizuno, ${ }^{1} \mathrm{MD}$
}

\begin{abstract}
SUMMARY
Plaque disruption, which may be associated with some coronary risk factors, plays a key role in the development of acute coronary syndromes and progression of atherosclerosis. However, the clinical profile of asymptomatic plaque disruption in stable ischemic heart disease has not been well evaluated. The aim of the present study was to investigate the frequency and determinants of silent plaque disruption (SPD) in patients with stable ischemic heart disease using coronary angioscopy. Forty-one patients with stable angina or old myocardial infarction (OMI) without any complaints within 3 months were included in the present study. Angioscopy was successfully performed through 49 nonischemic related coronary arteries. The presence of SPD and coronary risk factors were recorded. Silent plaque disruption was found in 12 patients with stable ischemic heart disease $(12 / 41,29.3 \%)$, and the frequency of SPD in nonischemic related coronary arteries was $26.5 \%(13 / 49)$. A significantly higher frequency of SPD was noted in yellow plaques than in white plaques (35.3\% versus 6.7\%, $P=0.043$ ). Overall, the independent clinical risk factors of SPD in nonischemic related coronary arteries were diabetes mellitus $(P=0.018$; OR, $18.8209 ; 95 \% \mathrm{CI}, 1.6525$ to 214.3523$)$ and hypertension $(P=0.0313$; OR, $6.6485 ; 95 \%$ CI, 1.1850 to 37.3019$)$. These results suggest silent plaque disruption was commonly observed in nonischemic related coronary arteries in patients with stable ischemic heart disease and its determinants were diabetes mellitus and hypertension. (Int Heart J 2010; 51: 383-387)
\end{abstract}

Key words: Plaque disruption, Angioscopy, Ischemic heart disease, Risk factors, Hypertension, Diabetes mellitus

A cute coronary syndrome (ACS) is a special disease spectrum of coronary artery diseases, which includes unstable angina, acute myocardial infarction, and sudden death, and is the major cause of cardiovascular death. Atherosclerotic plaque disruption, vascular spasm and the consequent platelet adhesion, aggregation and secondary thrombosis are the major pathophysiological mechanisms of acute coronary syndrome. Among them, coronary arterial plaque disruption is considered to play the key role in the cascade of acute coronary syndrome. ${ }^{1)}$

However, the plaque disruption may also heal without any symptoms. Autopsy studies have observed plaque disruption in approximately $10 \%$ of patients who died from noncardiac causes and without cardiac symptoms. ${ }^{2)}$ Although clinically silent, plaque disruption accompanied by mural thrombus formation may play a role in rapid plaque progression. ${ }^{3)}$ Moreover, silent plaque disruption in nonculprit lesions may be an indicator of extensive coronary instability which is often underestimated by angiography. Intravascular ultrasound (IVUS) study of patients within 30 days of ACS showed that approximately $79 \%$ of cases had plaque disruption located on the non- culprit lesions. ${ }^{4}$

It is well-known that coronary risk factors, such as hypertension, hyperlipidemia, smoking, and diabetes mellitus induce atherosclerosis and controlling these risk factors may also be associated with the modification of plaque vulnerability. ${ }^{5-7)}$ However, whether these risk factors can also affect the development of coronary silent plaque disruption has not yet been well addressed.

Although there have been studies that utilized IVUS to evaluate the incidence and clinical presentation of single and multiple plaque disruption in patients with ACS, or AMI, ${ }^{8,9)}$ there is little evidence concerning the clinical characteristics of silent plaque disruption in nonischemic related coronary arteries in patients with stable ischemic heart disease. In the present study, we used angioscopy, which has extremely sensitive detector of thrombus and intimal surface irregularities, to investigate the incidence of silent plaque disruption of nonischemic related coronary arteries and evaluate the association between coronary risk factors and silent plaque disruption in patients with stable ischemic heart disease.

From the ${ }^{1}$ First Department of Internal Medicine, Nippon Medical School, Tokyo and ${ }^{2}$ Department of Internal Medicine, Chiba Hokusoh Hospital, Nippon Medical School, Chiba, Japan.

Address for correspondence: Kyoichi Mizuno, MD, First Department of Internal Medicine, Nippon Medical School, 1-1-5 Sendagi, Bunkyo-ku, Tokyo 113-8602, Japan.

Received for publication April 6, 2010.

Revised and accepted September 6, 2010. 


\section{MethodS}

Study population: Forty-one patients (34 men and 7 women, age: $57.9 \pm 9.6$ years) with stable angina or OMI without any complaints within the previous 3 months were included in the study. Stable angina pectoris (SAP) was defined as no change in frequency, duration, or intensity of symptoms within 3 months before the angioscopy. Data on patient characteristics were collected after hospital admission. Hypertensive patients in this study were defined as those with blood pressure $>$ $140 / 90 \mathrm{mmHg}$ or those already taking antihypertensive drugs. The criteria for hyperlipidemia (hypertriglyceridemia and/or hypercholesterolemia) were based on the Japan Atherosclerosis Society Guideline $^{10)}$ (a fasting serum TG level $\geq 150 \mathrm{mg} / \mathrm{dL}$ and a fasting serum TC level $\geq 220 \mathrm{mg} / \mathrm{dL}$ ) or those already taking lipid-lowering drugs. Diabetic patients were defined as those with fasting blood glucose $>126 \mathrm{mg} / \mathrm{dL}$ or those already receiving drug therapy for diabetes mellitus. Hyperuricemia was defined as a serum uric acid level of $\geq 7.0 \mathrm{mg} / \mathrm{dL}$. Obesity was defined as a body mass index of $>26.4 \mathrm{~kg} / \mathrm{m}^{2}$. Ischemic related coronary artery was identified by the combination of the electrocardiographic findings, nuclear imaging tests, left ventricle wall motion abnormalities on echocardiography, and angiographic lesion morphology.

Coronary angioscopic procedure: We examined nonischemic related coronary arteries using coronary angioscopy. An angioscopic catheter (Vecmova Neo, FiberTech Co., Chiba, Japan) was used as previously reported. ${ }^{11)}$ Prior to observation, the white balance was adjusted for color correction. Light power was adjusted to avoid reflection and to obtain images with adequate brightness for determination of plaque color. After routine coronary angiography, an additional $100 \mathrm{U} / \mathrm{kg}$ heparin was administered, and an 8F guiding catheter was used to engage the coronary artery. During angioscopic observation, an exclusive assistant adjusted the light power to keep a regular degree of brightness on the target plaque. Angioscopic images and

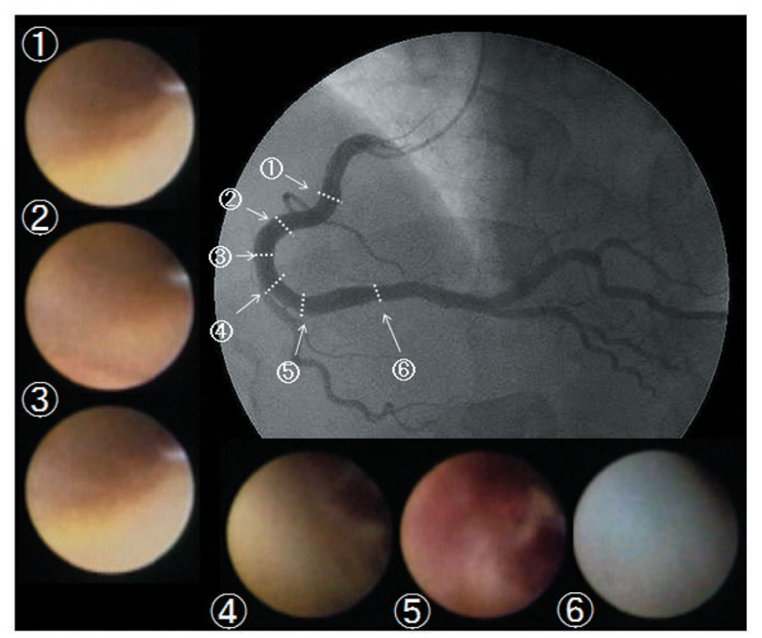

Figure 1. Angiography and angioscopy results in a patient with stable ischemic heart disease. Angiography showed $25 \%$ stenosis in the mid-segment of the right coronary artery, and coronary angioscopy revealed yellow plaque (1)-(3), plaque disruption (irregular surface with thrombus (4) (5)), and a white smooth surface (6) in this segment. fluoroscopy during the angioscopic observations were recorded simultaneously on digital videotape for later analysis. The exact position of the angioscopic catheter at the site of the target plaque was recorded by an angiogram. We were able to observe 49 nonischemic related arteries (single coronary artery was obtained in 31 patients and two coronary arteries in 8 patients). Other nonischemic related arteries were not suitable for angioscopic examination (eg, tortuous coronary arteries, small coronary arteries, or good angioscopic pictures to analyze were not obtainable).

Qualitative angioscopic analysis: The predominant color of the plaque, either yellow or white, the existence of a complex plaque, and the existence of thrombus were analyzed independently by two observers who were blinded to the clinical background of the patient.

Yellow plaques were defined as the yellow area on the lumen surface, which may have a smooth or irregular surface with or without protrusion into the coronary artery lumen. ${ }^{12)} \mathrm{A}$ lesion was defined as plaque disruption if it had an irregular appearance with visible cracks, fissures, or intimal flaps with or without thrombi. A lesion was considered undisrupted when its surface appeared smooth without irregularities and thrombi. Thrombi were defined as white or red material that had a cotton-like or ragged appearance, which may be protruding into the lumen or adhering to the lumen surface (Figure 1). ${ }^{13)}$

When any discordance was observed between the two observers, a third investigator read the images to obtain a consensus. Intraobserver agreement was measured by having an observer repeat the assessment of 20 images (presented in random order) after one week. The interobserver agreement was measured by comparing the assessment of 20 images by the two observers. The intraobserver agreements for the evaluated angioscopic items, namely, the yellow plaque, the plaque disruption, and the thrombus were $100 \%, 95 \%$, and $95 \%$, respectively. The interobserver agreements of those items were $97 \%$, $95 \%$, and $92 \%$, respectively.

Quantitative angiographic analysis: Quantitative angiographic measurements were performed using digital angiograms that were analyzed off-line with an automated edge-detection system (CMS, Medis Medical Imaging System, Nuenen, The Netherlands). The minimum luminal diameter, average reference diameter at distal/proximal adjacent reference segments (5 $\mathrm{mm}$ ) of the lesion, and percent diameter stenosis were measured from end-diastolic frames and the projection that demonstrated the highest stenotic site.

Statistical analysis: Statistical analysis was performed with SPSS program. Data are presented as frequencies or the mean \pm SD. Comparison was performed with Pearson's $\chi^{2}$ or Fisher's exact test and unpaired Student's $t$ test or ANOVA. Multivariate logistic regression analysis was performed to assess independent clinical predictors for silent plaque disruption of the nonischemic related coronary arteries. A probability value of $P$ $<0.05$ was considered statistically significant.

\section{RESULTS}

Comparison of clinical characteristics and coronary risk factors between patients with and without silent plaque disruption: Baseline clinical characteristics and coronary risk factors were analyzed between patients with or without SPD as shown in 
Table I. Baseline Clinical Characteristics and Coronary Risk Factors Comparing Patients With and Without Silent Plaque Disruption

\begin{tabular}{|c|c|c|c|}
\hline & $\begin{array}{c}\mathrm{SPD}(+) \\
n=12\end{array}$ & $\begin{array}{l}\text { SPD (-) } \\
n=29\end{array}$ & $P$ \\
\hline Age (years) mean $\pm \mathrm{SD}$ & $59.3 \pm 10.6$ & $57.3 \pm 9.3$ & 0.565 \\
\hline Gender, male, $n(\%)$ & $11(91.6 \%)$ & $23(79.3 \%)$ & 0.651 \\
\hline OMI, $n(\%)$ & $8(66.7 \%)$ & $24(82.8 \%)$ & 0.408 \\
\hline \multicolumn{4}{|l|}{ Medications } \\
\hline ACE inhibitors, $n(\%)$ & $4(33.3 \%)$ & $7(24.1 \%)$ & 0.311 \\
\hline $\mathrm{ARB}, n(\%)$ & $1(8.3 \%)$ & $6(20.7 \%)$ & 0.225 \\
\hline Beta-blocker, $n(\%)$ & $7(58.3 \%)$ & $11(37.9 \%)$ & 0.292 \\
\hline Antiplatelet agent, $n(\%)$ & $12(100 \%)$ & $26(89.7 \%)$ & 0.337 \\
\hline $\begin{array}{l}\text { Antihyperlipidemia agents, } \\
n(\%)\end{array}$ & $5(41.7 \%)$ & $17(58.6 \%)$ & 0.131 \\
\hline $\begin{array}{l}\text { Calcium channel blockers, } \\
n(\%)\end{array}$ & $9(75.0 \%)$ & $18(62.1 \%)$ & 0.315 \\
\hline Nitrates, $n(\%)$ & $8(66.7 \%)$ & $17(58.6 \%)$ & 0.336 \\
\hline Oral hypoglycemics, $n(\%)$ & $4(33.3 \%)$ & $3(10.3 \%)$ & 0.165 \\
\hline Current smoker, $n(\%)$ & $3(25.0 \%)$ & $9(31.0 \%)$ & 1.000 \\
\hline Former smoker, $n(\%)$ & $5(41.7 \%)$ & $6(20.7 \%)$ & 0.247 \\
\hline Family history, $n(\%)$ & $5(41.7 \%)$ & $8(27.6 \%)$ & 0.469 \\
\hline Hyperlipidemia, $n(\%)$ & $10(83.3 \%)$ & $25(86.2 \%)$ & 1.000 \\
\hline Hypertension, $n(\%)$ & $9(75.0 \%)$ & $8(27.6 \%)$ & 0.013 \\
\hline Hyperuricemia, $n(\%)$ & $4(33.3 \%)$ & $9(31.0 \%)$ & 1.000 \\
\hline Diabetes, $n(\%)$ & $7(58.3 \%)$ & $5(17.2 \%)$ & 0.020 \\
\hline $\mathrm{HbA} 1 \mathrm{c}(\%)$, mean $\pm \mathrm{SD}$ & $6.8 \pm 0.7$ & $5.5 \pm 0.8$ & 0.003 \\
\hline Obesity, $n(\%)$ & $6(50.0 \%)$ & $15(51.7 \%)$ & 1.000 \\
\hline $\begin{array}{l}\text { Body mass index }(\mathrm{kg} / \mathrm{m}) \text {, } \\
\text { mean } \pm \mathrm{SD}\end{array}$ & $25.6 \pm 3.5$ & $24.6 \pm 3.3$ & 0.457 \\
\hline $\begin{array}{l}\text { Total cholesterol }(\mathrm{mg} / \mathrm{dL}) \\
\text { mean } \pm \mathrm{SD}\end{array}$ & $204.0 \pm 23.8$ & $205.3 \pm 39.6$ & 0.916 \\
\hline HDL-C $(\mathrm{mg} / \mathrm{dL})$, mean $\pm \mathrm{SD}$ & $48.1 \pm 15.1$ & $48.1 \pm 11.3$ & 0.990 \\
\hline $\begin{array}{l}\text { Triglycerides }(\mathrm{mg} / \mathrm{dL}) \\
\text { mean } \pm \mathrm{SD}\end{array}$ & $150.3 \pm 75.1$ & $167.3 \pm 111.9$ & 0.630 \\
\hline
\end{tabular}

SPD indicates silent plaque disruption; OMI, old myocardial infarction; $\mathrm{ACE}$, angiotensin converting enzyme; $\mathrm{ARB}$, angiotensin II receptor blocker; HbA1c, hemoglobin Alc; and HDL-C, high density lipoprotein-cholesterol.

Table I. There were no significant differences in age, gender, incidence of OMI, or medication between the two groups. The group with SPD included more patients with diabetes mellitus (58.3\% versus $17.2, P=0.020)$, hypertension $(75.0 \%$ versus $27.6 \% P=0.013)$, and higher $\mathrm{HbA} 1$ levels $(6.8 \pm 0.7$ versus $5.5 \pm 0.8, P=0.003$ ).

Angiographic findings comparing patients with and without silent plaque disruption: Quantitative coronary angiographic measurements comparing plaques with and without silent plaque disruption (SPD) are shown in Table II. There were no significant differences in lesion site, mean reference diameter, minimum lumen diameter, or percent diameter stenosis between SPD and non-SPD plaques.

Angioscopic findings: Thirteen silent plaque disruptions were found in 13 nonischemic related coronary arteries in 12 patients. The frequency of silent plaque disruption in patients with stable ischemic heart disease in the present study was $29.3 \%(12 / 41)$, and the frequency of silent plaque disruption in nonischemic related coronary arteries was $26.5 \%$ (13/49). Among the 13 silent plaque disruptions, 5 cases had irregular surfaces, 4 cases had visualized thrombi, and the remaining 4 cases had irregular surfaces accompanied by thrombi. Fortynine coronary plaques were detected, 34 of which were yellow
Table II. Angiographic Findings Comparing With and Without Silent Plaque Disruption

\begin{tabular}{|c|c|c|c|}
\hline & $\begin{array}{c}\operatorname{SPD}(+) \\
n=13\end{array}$ & $\begin{array}{c}\operatorname{SPD}(-) \\
n=36\end{array}$ & $P$ \\
\hline \multirow[t]{2}{*}{ Number of vessel disease } & $10(83.3 \%)$ & $27(93.1 \%)$ & 0.567 \\
\hline & $2(16.7 \%)$ & $2(6.9 \%)$ & \\
\hline \multicolumn{4}{|l|}{ Non-ischemic-related arteries } \\
\hline Right coronary artery, $n(\%)$ & $4(30.8)$ & $13(36.1)$ & \\
\hline $\begin{array}{l}\text { Left anterior descending artery, } \\
n(\%)\end{array}$ & $6(46.2)$ & $13(36.1)$ & 0.816 \\
\hline Left circumflex artery, $n(\%)$ & $3(23.0)$ & $10(27.8)$ & \\
\hline \multicolumn{4}{|l|}{ Quantitative coronary angiography } \\
\hline $\begin{array}{l}\text { Mean reference diameter }(\mathrm{mm}) \\
\text { mean } \pm \mathrm{SD}\end{array}$ & $2.6 \pm 0.6$ & $2.8 \pm 0.6$ & 0.612 \\
\hline $\begin{array}{l}\text { Minimum lumen diameter }(\mathrm{mm}) \text {, } \\
\text { mean } \pm \text { SD }\end{array}$ & $1.8 \pm 0.4$ & $2.1 \pm 0.6$ & 0.198 \\
\hline $\begin{array}{l}\text { Diameter stenosis }(\%) \\
\text { mean } \pm \mathrm{SD}\end{array}$ & $28.6 \pm 17.1$ & $24.8 \pm 17.5$ & 0.565 \\
\hline
\end{tabular}

SPD indicates silent plaque disruption.

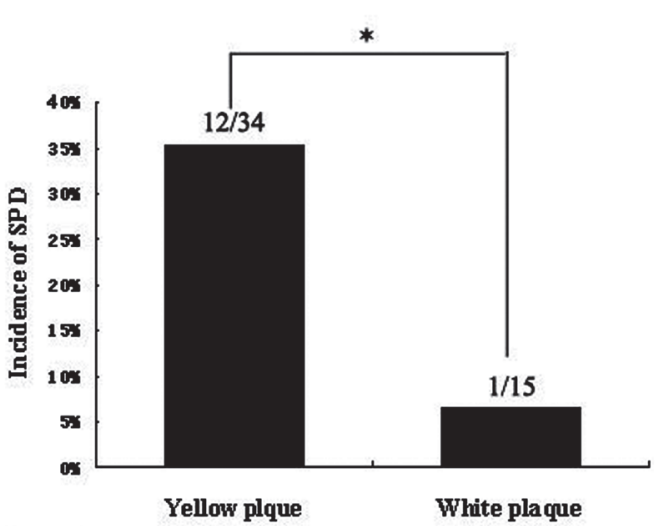

Figure 2. Comparison of silent plaque disruption (SPD) in nonischemiarelated arteries with yellow plaques and those with white plaques. The incidence of silent plaque disruptions in yellow plaques was higher than that in white plaques. $* P=0.043$ versus white plaque group.

Table III. Multivariate Analysis of Predictors of Silent Plaque Disruption

\begin{tabular}{lccccc}
\hline Variable & Coefficient & $\begin{array}{c}\text { Standard } \\
\text { error }\end{array}$ & $\begin{array}{c}\text { Odds } \\
\text { ratio }\end{array}$ & $\begin{array}{c}95 \% \text { confidence } \\
\text { interval }\end{array}$ & $P$ \\
\hline Age & 0.5976 & & & & 0.4395 \\
Current smoker & 0.0070 & & & & 0.9785 \\
Former smoker & 2.1547 & & & & 0.1421 \\
Diabetes & 2.9350 & 1.2412 & 18.8209 & $1.6525-214.3523$ & 0.0180 \\
Family history & 2.1369 & & & & 0.0843 \\
Gender & 0.0290 & & & & 0.8647 \\
Hyperlipidemia & 0.9258 & & & & 0.3360 \\
Hypertension & 1.8944 & 0.8799 & 6.6485 & $1.1850-37.3019$ & 0.0313 \\
Hyperuricemia & 0.0008 & & & & 0.9776 \\
Obesity & 0.5747 & & & & 0.4484 \\
\hline
\end{tabular}

plaques. The incidence of silent plaque disruptions in yellow plaques was significantly higher than that in white plaques (35.3\% versus $6.7 \% * P=0.043$ ) (Figure 2). 
Correlation of coronary risk factors and silent plaque disruption: Multivariate logistic regression analysis was performed to determine the independent clinical risk factors of silent plaque disruption (Table III). For all the patients, the independent predictors of plaque disruption were diabetes mellitus $(P=$ 0.018; OR, 18.8209; 95\% CI, 1.6525 to 214.3523$)$ and hypertension ( $P=0.0313$; OR, $6.6485 ; 95 \% \mathrm{CI}, 1.1850$ to 37.3019$)$.

\section{Discussion}

Plaque disruption in culprit coronary arteries is by far the most frequent cause of coronary thrombosis and is the underlying pathophysiological mechanism for acute coronary syndrome (ACS). ${ }^{14)}$ However, multiple complex plaques with plaque disruption in nonculprit lesions may also be associated with an increased incidence of recurrent ACS in patients with acute myocardial infarction. ${ }^{15)}$ The repeated plaque disruptions in nonculprit lesions that heal without any symptoms may result in a significant increase in plaque burden and percent stenosis. ${ }^{16)}$ Moreover, recently a study observed that the multiplicity of vulnerable plaques in nonculprit vessels was significantly correlated with future critical cardiac events. ${ }^{17)}$ Therefore, the in vivo study of the incidence and influencing factors of silent plaque disruption in nonischemic related coronary arteries at different stages of coronary heart disease will help to further clarify the underlying mechanisms of plaque disruption and assist with a clinical prognosis, and will certainly help in designing preventive therapeutic strategies. Our study focused on the evaluation of nonischemic related coronary artery silent plaque disruption in clinically asymptomatic patients with OMI and SAP using angioscopy. Among the 41 patients, silent plaque disruptions at nonculprit sites were noted in 12 (29.3\%) patients and in 13 arteries among 49 nonischemic related coronary arteries being angioscopically examined. The findings of the present study contrast sharply with those of another published 3-vessel IVUS study which reported that plaque disruptions in nontarget coronary arteries occurred in 5\% of SAP patients. ${ }^{18)}$ The reason for this difference may be attributed to the exclusion of the OMI patients in the previous IVUS study and the difference in detection sensitivity between IVUS and angioscopy.

The risk factors for atherosclerosis, including diabetes mellitus and hypertension, have been known for many years. Although we know a great deal about how these factors contribute to the development of coronary atherosclerosis, the relationship between these factors and silent plaque disruption in patients with OMI and SAP are still unknown. In the present study, we found that diabetes mellitus and hypertension are independent clinical risk factors for silent plaque disruption in patients with OMI and SAP. Autopsy studies have shown that plaques with disruption have much larger lipid cores and less fibrous tissue than plaques with an intact surface. ${ }^{19)}$ One of the key processes of plaque disruption is the formation of the lipidcore and the thinning of the fibrous caps. In atherectomy specimens, the necrotic areas of plaque are increased in de novo lesions in persons with diabetes mellitus. ${ }^{20)}$ Similar findings were also observed in a recent in vivo intravascular ultrasound (IVUS) study in stable angina pectoris patients with type 2 diabetes mellitus. ${ }^{21)}$ Furthermore, diabetic patients were characterized by a higher level of apoptosis of vascular smooth muscle cells (VSMC), higher nuclear factor-kappa B (NF-B) activation, and higher metalloproteinases-9 (MMP-9) levels along with a lesser interstitial collagen content. ${ }^{22)}$ These changes might also be involved in future plaque disruption. Hypertension and atherosclerotic plaque progression in the arteries have similar pathological changes, that is, a vessel wall inflammatory response and endothelial cell damage. ${ }^{23)}$ Autopsy studies have revealed hypertension was significantly associated with the incidence of asymptomatic coronary thrombosis and plaque disruption in patients with noncardiac death. ${ }^{24)}$ The elevated systolic forces from cardiac hypertrophy, ${ }^{25)}$ shear stress, and increase in circumferential wall tension ${ }^{26,27)}$ in hypertensive patients may take part in the worsening of the plaque progression and disruption.

The intensity of the yellow color of plaques, which can be evaluated by angioscopy, is known to be determined by the thickness of the fibrous cap. The cap of intense yellow color plaques is very $\operatorname{thin}^{28)}$ and is associated with plaque vulnerability. ${ }^{29,30)}$ In the present study, for patients with OMI and stable angina, yellow plaques had a higher incidence of silent plaque disruption compared to white plaques. Therefore, through better identification of the yellow plaques, angioscopy would be useful for the detection of patients who are at high risk of suffering plaque disruption in a nonischemic related coronary artery.

Limitations: The results might not apply to all patients with stable ischemic heart disease because not all nonculprit coronary arteries were obtained by successful angioscopic examination in the present study. Also, since there was no follow-up, we were unable to determine whether the detection of plaque disruptions at nonculprit sites could have clinical consequences.

Conclusion: Silent plaque disruptions were commonly observed in nonischemic related coronary arteries in patients with stable ischemic heart disease. Its determinants were diabetes mellitus and hypertension. These findings may help to establish an aggressive medical approach that attempts to control diabetes mellitus and hypertension in patients with OMI and stable angina pectoris to stabilize the plaque, prevent its progression, and reduce the incidence of acute coronary syndrome.

\section{REFERENCES}

1. Libby P. Molecular and cellular mechanisms of the thrombotic complications of atherosclerosis. J Lipid Res 2009; 50: S352-7.

2. Davies MJ, Bland JM, Hangartner JR, Angelini A, Thomas AC. Factors influencing the presence or absence of acute coronary artery thrombi in sudden ischemic death. Eur Heart J 1989; 10: 203-8.

3. Burke AP, Kolodgie FD, Farb A, et al. Healed plaque ruptures and sudden coronary death: evidence that subclinical rupture has a role in plaque progression. Circulation 2001; 103: 934-40.

4. Rioufol G, Finet G, Ginon I, et al. Multiple atherosclerotic plaque rupture in acute coronary syndrome: a three-vessel intravascular ultrasound study. Circulation 2002; 106: 804-8.

5. Hong MK, Mintz GS, Lee CW, et al. Serial intravascular ultrasound evidence of both plaque stabilization and lesion progression in patients with ruptured coronary plaques: effects of statin therapy on ruptured coronary plaque. Atherosclerosis 2007; 191: 107-14.

6. Rabbani R, Topol EJ. Strategies to achieve coronary arterial plaque stabilization. Cardiovasc Res 1999; 41: 402-17. (Review)

7. Hiro T, Kimura T, Morimoto T, et al. Effect of intensive statin therapy on regression of coronary atherosclerosis in patients with 
acute coronary syndrome: a multicenter randomized trial evaluated by volumetric intravascular ultrasound using pitavastatin versus atorvastatin (JAPAN-ACS [Japan assessment of pitavastatin and atorvastatin in acute coronary syndrome] study). J Am Coll Cardiol 2009; 54: 293-302

8. Ge J, Chirillo F, Schwedtmann J, et al. Screening of ruptured plaques in patients with coronary artery disease by intravascular ultrasound. Heart 1999; 81: 621-7.

9. Rioufol G, Finet G, Ginon I, et al. Multiple atherosclerotic plaque rupture in acute coronary syndrome: a three-vessel intravascular ultrasound study. Circulation 2002; 106: 804-8.

10. Hata Y, Mabuchi H, Saito Y, et al. Report of the Japan Atherosclerosis Society (JAS) Guideline for Diagnosis and Treatment of Hyperlipidemia in Japanese adults. J Atheroscler Thromb 2002; 9: $1-27$.

11. Sakai S, Mizuno K, Yokoyama S, et al. Morphologic changes in infarct-related plaque after coronary stent placement: a serial angioscopy study. J Am Coll Cardiol 2003; 42: 1558-65.

12. Mizuno K, Miyamoto A, Satomura K, et al. Angioscopic coronary macromorphology in patients with acute coronary disorders. Lancet 1991; 337: 809-12.

13. Mizuno K, Satomura K, Miyamoto A, et al. Angioscopic evaluation of coronary-artery thrombi in acute coronary syndromes. $\mathrm{N}$ Engl J Med 1992; 326: 287-91.

14. Schaar JA, Muller JE, Falk E, et al. Terminology for high-risk and vulnerable coronary artery plaques. Report of a meeting on the vulnerable plaque, June 17 and 18, 2003, Santorini, Greece. Eur Heart J 2004; 25: 1077-82. (Review)

15. Goldstein JA, Demetriou D, Grines CL, Pica M, Shoukfeh M, O'Neill WW. Multiple complex coronary plaques in patients with acute myocardial infarction. N Engl J Med 2000; 343: 915-22.

16. Burke AP, Kolodgie FD, Farb A, et al. Healed plaque ruptures and sudden coronary death: evidence that subclinical rupture has a role in plaque progression. Circulation 2001; 103: 934-40.

17. Kim SH, Hong MK, Park DW, et al. Impact of plaque characteristics analyzed by intravascular ultrasound on long-term clinical outcomes. Am J Cardiol 2009; 103: 1221-6.

18. Hong MK, Mintz GS, Lee CW, et al. Comparison of coronary plaque rupture between stable angina and acute myocardial infarc- tion: a three-vessel intravascular ultrasound study in 235 patients. Circulation 2004; 110: 928-33.

19. Libby P, Theroux P. Pathophysiology of coronary artery disease. Circulation 2005; 111: 3481-8. (Review)

20. Creager MA, Lüscher TF, Cosentino F, Beckman JA. Diabetes mellitus and vascular disease: pathophysiology, clinical consequences, and medical therapy: Part I. Circulation 2003; 108: 152732. (Review)

21. Nasu K, Tsuchikane E, Katoh O, et al. Plaque characterisation by Virtual Histology intravascular ultrasound analysis in patients with type 2 diabetes. Heart 2008; 94: 429-33.

22. Marfella R, Di Filippo C, Baldi A, et al. The vascular smooth muscle cells apoptosis in asymptomatic diabetic carotid plaques: role of glycemic control. J Am Coll Cardiol 2006; 47: 2118-20.

23. Graundy SM. Inflammation, hypertension and the metabolic syndrome. JAMA 2003; 290: 3000-2.

24. Sato Y, Hatakeyama K, Marutsuka K, Asada Y. Incidence of asymptomatic coronary thrombosis and plaque disruption: comparison of non-cardiac and cardiac deaths among autopsy cases. Thromb Res 2009; 124: 19-23.

25. Burke AP, Farb A, Liang YH, Smialek J, Virmani R. Effect of hypertension and cardiac hypertrophy on coronary artery morphology in sudden cardiac death. Circulation 1996; 94: 3138-45.

26. Caro CG, Fitz-Gerald JM, Schroter RC. Arterial wall shear and distribution of early atheroma in man. Nature 1969; 223: 1159-60.

27. Dirksen MT, van der Wal AC, van der Berg FM, van der Loos CM, Becker AE. Distribution of inflammatory cells in atherosclerotic plaques relates to the direction of flow. Circulation 1998; 98 2000-3.

28. Takano M, Jang IK, Inami S, et al. In vivo comparison of optical coherence tomography and angioscopy for the evaluation of coronary plaque characteristics. Am J Cardiol 2008; 101: 471-6.

29. Kawasaki M, Takatsu H, Noda T, et al. In vivo quantitative tissue characterization of human coronary arterial plaques by use of integrated backscatter intravascular ultrasound and comparison with angioscopic findings. Circulation 2002; 105: 2487-92.

30. Ueda Y, Ohtani T, Shimizu M, Hirayama A, Kodama K. Assessment of plaque vulnerability by angioscopic classification of plaque color. Am Heart J 2004; 148: 333-5. 